\title{
A Study of the Selection and Control of Exercise Casualties for Hospital Collective Training
}

Col K Clarke,

TD, QHS, MB, BS, FFARCS, DA, L/RAMC, Project Officer HO AMS TA

Brig R G Robinson, QHS, MB, ChB, MFCM, DTM\&H, L/RAMC, Commander HQ AMS TA

HQ AMS TA, Keogh Barracks, Ash Vale, Aldershot, Hants

SUMMARY: A project sponsored by HQ AMS TA and executed by an experienced TA Commanding Officer enhanced $\odot$

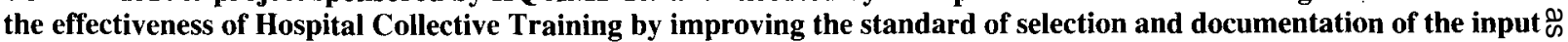
of exercise casualties, and set up the basis of a comprehensive library of casualty cards for future use.

\section{Introduction}

Up to and including 1985 there have been complaints about the selection, control, documentation and administration of the exercise casualties on Folding Bed, Mini Mash, Petit Mash and other exercises.

The staffs of the Territorial Army hospitals work in teams in which the medical and nursing officers come from sophisticated hospitals of the National Health Service or private sector, while the servicemen and servicewomen come from employments outside hospitals.

It is on exercises that the servicemen and servicewomen have their own opportunity to be taught the application of nursing skills by the officers with whom they work, and the officers have the chance to accustom themselves to using the equipment available in a wartime hospital, and prepare themselves to treat battle casualties who have been wounded some time previously and transported over long distances.

Commander HQ AMS TA set up a project to enhance the benefit of these exercises by preparing a comprehensive plan for selection, preparation and injection of appropriate exercise casualties into hospitals taking part in collective training, so as to make the exercises as interesting, realistic, credible and stimulating as possible.

The project officer was appointed and the charter for the project promulgated by Headquarters Army Medical Services Territorial Army in July 1984.

The Project Officer had commanded a TA General Hospital, had had cause to complain about the exercise casualties on previous exercises and identified the aims to be pursued as -

1. To produce casualties which were appropriate to the battle scene and the role of the unit.

2. To produce casualties who were happy at the end of the day and who felt that they had learnt something.

3 . To produce a library of $F$ Med 26 series of cards which could be used as a template for future exercises.
It was recognised that -

1. It is confusing for a General Hospital to apply primary treatment and evacuate as if it were a Field Hospital.

2. The DS must organise the feeding of exercise $\vec{N}$ casualties before they enter the casualty chain. It is unrealistic, for instance, to feed GSW abdomen in resuscitation or on the operating table.

3. Sometimes in the past casualty simulation has been inappropriate or absent.

4. The AMS is dependent on other Arms to product casualties and unless they are well cared for and leade something, commanders will not allow their soldiers po act as casualties. This refusal to participate onfy $\overrightarrow{ }$ occurred once during one of the 1985 Petit Maflळ exercises but it spoilt the exercise to a large extent.

\section{Method}

An initial approach was made to the Director of Army Surgery for an up to date projection of the proportions of wounds by site and priority (see Table I).

From this and the number of casualties to be $\overrightarrow{\vec{O}}$ available, making allowance for recycling, the cross 3 section of casualties to be admitted to each General Hospital through the formal chain of evacuation and? from local incidents was calculated (see Tables II, III and IV). Allowance was made for training needs, including the requirement to include a number of medical cases. Similar Tables were prepared for Field $\vec{\sigma}$ Hospitals.

Casualties to match the requirement thus identified were selected from the "Lillywhite List".

The "Lillywhite List" of battle casualties had been. derived from the currently accepted proportions of $\frac{O}{3}$ casualties by diagnosis and perusal of the case notes and case histories of casualties from the Arab-Israeli conflict? and other sources, clinical details and survival data being $\rightarrow$ largely derived from actual patients.

$F$ Med 26s were then prepared for the casualties selected, fully documented to conform with the Casualty Treatment Regimes and the Field Surgery Pocket Book. N 
Table I

Breakdown of 1000 Surgical Battle Casualties into Casualty Types and Priorities

(Taken from Annex D to D/AMD/78/3/8 (DA Surg) of 30 July 1984)

\begin{tabular}{lcccc}
\hline & Overall & P1 & P2 & P3 \\
\hline Abdo $(10 \%)$ & 100 & 20 & 80 & - \\
\hline Head and Neck $(10 \%)$ & 100 & 25 & 25 & 50 \\
\hline Burns $(10 \%)$ & 100 & 15 & 10 & 75 \\
\hline Chest $(5 \%)$ & 50 & 20 & 20 & 10 \\
\hline Limbs $(20 \%)$ & & & & \\
Arms & 200 & 35 & 25 & 140 \\
Legs (35\%) & 350 & 65 & 35 & 250 \\
\hline Multi/Misc (10\%) & 100 & 20 & 5 & 75 \\
\hline TOTALS & 1000 & 200 & 200 & 600 \\
& $(100 \%)$ & $(20 \%)$ & $(20 \%)$ & $(60 \%)$ \\
\hline
\end{tabular}

Table II

Cas Profile for RCZ General Hospitals

\begin{tabular}{llr}
\hline Cas from & $\begin{array}{c}\text { Documentation to cover RAP, } \\
\text { Fd Amb, Fd Hosp and Transit. } \\
\text { All P1 cases will be post-op. }\end{array}$ \\
\hline Abdo & P1 (post-op) & 2 \\
Head \& Neck: & P2 & 50 \\
& P1 (post-op) & 2 \\
Burns: & P2 & 15 \\
& P3 & 30 \\
Chest: & P1 (post-op) & 2 \\
& P2 & 5 \\
& P3 & 45 \\
Upper Limb: & P1 (post-op) & 2 \\
& P2 & 10 \\
& P3 & 5 \\
Lower Limb: & P1 (post-op) & 3 \\
& P2 & 15 \\
& P3 & 85 \\
Multiple/Misc: & P1 (post-op) & 6 \\
& P2 & 20 \\
& P3 & 155 \\
& P1 (post-op) & 2 \\
& P3 & 2 \\
& & \\
& &
\end{tabular}


Table III

Casualty Profile for RCZ General Hospital

\begin{tabular}{|c|c|c|}
\hline \multicolumn{3}{|l|}{$\begin{array}{l}\text { Cas from } \\
\text { RCZ Fd Ambs: }\end{array}$} \\
\hline Abdo & $\begin{array}{l}\text { P1 } \\
\text { P2 }\end{array}$ & $\begin{array}{l}1 \\
4\end{array}$ \\
\hline Head \& Neck: & $\begin{array}{l}\text { P1 } \\
\text { P2 } \\
\text { P3 }\end{array}$ & $\begin{array}{l}1 \\
1 \\
3\end{array}$ \\
\hline Burns: & $\begin{array}{l}\text { P1 } \\
\text { P2 } \\
\text { P3 }\end{array}$ & $\begin{array}{l}1 \\
1 \\
4\end{array}$ \\
\hline Chest: & $\begin{array}{l}\text { P1 } \\
\text { P2 } \\
\text { P3 }\end{array}$ & $\begin{array}{l}2 \\
2 \\
1\end{array}$ \\
\hline Upper Limb: & $\begin{array}{l}\text { P1 } \\
\text { P2 } \\
\text { P3 }\end{array}$ & $\begin{array}{l}2 \\
1 \\
6\end{array}$ \\
\hline Lower Limb: & $\begin{array}{l}\text { P1 } \\
\text { P2 } \\
\text { P3 }\end{array}$ & $\begin{array}{r}2 \\
2 \\
10\end{array}$ \\
\hline Multiple/Misc: & $\begin{array}{l}\text { P1 } \\
\text { P2 } \\
\text { P3 }\end{array}$ & $\begin{array}{l}1 \\
1 \\
4\end{array}$ \\
\hline Medical: & & $\frac{25}{75}$ \\
\hline
\end{tabular}

Table IV

Casualty Profile for RCZ General Hospitals

\begin{tabular}{llr}
\hline $\begin{array}{l}\text { Cas from } \\
\text { Local incidents: }\end{array}$ & & Undocumented \\
\hline Abdo & P1 & 1 \\
& P2 & 2 \\
Head \& Neck: & P2 & 1 \\
& P3 & 1 \\
Burns: & P2 & 1 \\
& P3 & 2 \\
Chest: & P1 & 1 \\
& P2 & 1 \\
Upper Limb: & P1 & 1 \\
& P3 & 3 \\
Lower Limb: & P1 & 1 \\
& P2 & 5 \\
Multiple/Misc: & P3 & 1 \\
& P3 & 3 \\
Medical: & & 15 \\
Battleshock: & & 10 \\
& & 50
\end{tabular}


Suitable cases were selected for evacuation from the forward area via RAP, Field Ambulance and Field Hospital; and for local incidents and medical cases sent in from the local RCZ Field Ambulance.

On several occasions the same injury from the "Lillywhite List" was processed as both satisfactory throughout or having "Gone Off". This proved valuable in varying the casualty input to conform to the training requirement of the Unit.

Throughout reference was made to the Tactical Doctrines for forward and rear Combat Zone Hospitals.

\section{Ex Petit Mash 85 - Phase I}

Under the Project Charter the system was tested during the 1985 Petit Mash series of exercises, the Project Officer becoming Casualty Control Officer and Commander HQ AMS TA Exercise Director. Each exercise lasted from Wednesday to Sunday. At the start of the exercise we had available some 300 cards, 200 as if from the FEBA and 100 from locally occurring incidents.

The initial input of casualties was selected so as to help the Hospital Departments get into gear smoothly. (see Table V).

Realism was maintained by local incidents enabling there to be a satisfactory casualty input during the time when casualties from the FEBA would still be in the evacuation chain. This allowed us to keep the casualty proportions reasonably accurate without straining the war picture too greatly.

For each input of casualties it was determined -

1. Where and when fighting would occur.

2. Distances between medical units, and time casualties would take to be evacuated between them.

3. Transit times within units, taking account of casualty loading, and a Table prepared giving the the diagnosis, priority and timings for each casualty (see Table VI).

Photostat copies of the library cards were endorsed with times and dates of injury, time of arrival in each medical unit, and treatments given (see Figure 1).

The F Med 26s were passed to the Casualty Simulation Team as early as possible. Once the casualties had been made up, appropriate splints and dressings were applied and names inserted on F Med 26 . They were admitted to the hospital in batches according to the DS "Pink".
Those reaching evacuation were subsequently recycled, usually with minor injuries to enable them to be released realistically in time for their planned RTU.

\section{Ex Petit Mash 85 - Phase II}

After a lull in the battle which permitted the change over of the soldiers detailed as exercise casualties, and enabled the hospital being exercised to do any reorganisation of its layout that was considered appropriate, the scenario led to a heightening of the battle with infantry, tank and artillery casualties being required. The selection and filling in of the F Med 26s became more difficult as the proportions of casualties had to be correct while the injury and unit had to be appropriate eg GSW - Infantry; burns - Armour; explosions Artillery.

The hard pressed Casualty Simulation Teams were becoming bored with the high proportion of legs and burns required to keep within the bounds of reality. Fortunately the "Pink" included sabotage and Spetznatz incidents from which Cas Control could allow freedom to their imagination and permit the Casualty Simulation Team to demonstrate their versatility in the direction of guard dog bites to buttocks and apparent drownings (Fig. $2 \& 3$ ).

It was during this phase that a local incident was introduced. This was an ambulance crash at the hospital gates and tested the efficiency of the hospital "Crash Teams". It also enabled the Casualty Simulation Team to exhibit their talents with injuries unencumbered by dressings, and gave a welcome respite to the authors of the F Med 26s.

Extra activity within the hospitals was generated by the Surgical Umpires making the condition of casualties awaiting evacuation deteriorate appropriately.

\section{Ex Petit Mash 85 - Phase III}

The exercises each ended with a heavy load of casualties provided by cadets. The gap between the departure of the soldiers provided under Regular Army Assistance and the arrival of the cadets was covered on the ad hoc basis by local AMS TA units. The numbers of enthusiastic and helpful cadets, apart from the one occasion when they failed to turn up, strained the capacity of the team of two "F Med 26 authors" to the

Table V

Ex Petit Mash 85

Initial Incidents

\begin{tabular}{|c|c|c|c|c|c|}
\hline Serial & Time & Incidents & Cas No & Diagnosis & Priority \\
\hline \multirow[t]{3}{*}{1} & 1700 & $\begin{array}{l}\text { Border Incident } \\
\text { (4th Bn Light Infantry) }\end{array}$ & 7 & $\begin{array}{l}\text { Shrapnel Wound } \\
\text { (left frontal) }\end{array}$ & 2 \\
\hline & & & 229 & GSW left forearm & 3 \\
\hline & & & 352 & Closed fracture femur & 3 \\
\hline
\end{tabular}


Table VI

Ex Petit Mash 85

Casualties from Battle Group Actions on Day 2

\begin{tabular}{|c|c|c|c|c|c|c|c|c|}
\hline \multirow{2}{*}{$\begin{array}{l}\text { Serial } \\
\text { and time }\end{array}$} & \multirow[b]{2}{*}{ Incident(s) } & \multirow[b]{2}{*}{ Cas No } & \multirow[b]{2}{*}{ Diagnosis } & \multirow[b]{2}{*}{ Priority } & \multicolumn{4}{|c|}{ Time of } \\
\hline & & & & & Wound & Rap & Fd Amb & Fd Hosp \\
\hline \multirow[t]{2}{*}{ Serial 12} & 1 Gordons) & 50 & Face & P3 & 1700 & 1730 & 1830 & 1930 \\
\hline & 2Para) in contact & 234 & Arm & P2 & & & 1830 & 1930 \\
\hline \multirow[t]{8}{*}{2115} & $9 / 12 \mathrm{~L})$ & 259 & Arm & P3 & 1700 & 1730 & 1815 & 1930 \\
\hline & & 261 & Arm \& Torso & P3 & 1700 & 1730 & 1830 & 1930 \\
\hline & $\operatorname{via} 7 \mathrm{Fd} \mathrm{Amb}$ & 281 & Leg & P2 & 1730 & 1815 & 1900 & 1945 \\
\hline & & 326 & Leg & P3 & 1730 & 1815 & 1900 & 1945 \\
\hline & & 336 & Leg \& Abdo & P3 & 1700 & 1745 & 1845 & 1930 \\
\hline & & 352 & Leg & P2 & 1900 & & 1915 & 2015 \\
\hline & & 435 & Burn & $\mathrm{P} 2$ & 1700 & 1745 & 1845 & 1930 \\
\hline & & 473 & Burn & P2 & 1700 & 1745 & 1845 & 1930 \\
\hline \multirow[t]{2}{*}{ Serial 13} & 2 R Anglian) & 42 & Head & P3 & 1900 & 1930 & 2030 & 2130 \\
\hline & $6 \mathrm{GR})$ in contact & 49 & Head & P3 & 1930 & 2000 & 2045 & 2145 \\
\hline \multirow[t]{18}{*}{2310} & $17 / 21 \mathrm{~L})$ & 76 & Chest & $\mathrm{P} 1$ & 1930 & 2000 & 2045 & 2145 \\
\hline & & 88 & Chest & $\mathrm{P} 2$ & 1900 & 1930 & 2030 & 2130 \\
\hline & via $8 \mathrm{Fd} \mathrm{Amb}$ & 147 & Abdo & $\mathrm{P} 2$ & 1900 & 1930 & 2030 & 2130 \\
\hline & & 224 & Arm & $\mathrm{P} 3$ & 1900 & 1930 & 2030 & 2130 \\
\hline & & 247 & Arm & $\mathrm{P} 2$ & 1930 & 2000 & 2045 & $2145 \stackrel{\subsetneq}{\varnothing}$ \\
\hline & & 253 & Arm & P3 & 1930 & 2000 & 2045 & $2145 \stackrel{?}{?}$ \\
\hline & & 264 & Arm & P3 & 1945 & 2015 & 2100 & $2145 \frac{T}{T}$ \\
\hline & & 265 & Arm & P3 & 1945 & 2015 & 2100 & $2145 \stackrel{\circ}{\frac{1}{1}}$ \\
\hline & & 277 & Knee & P3 & 2030 & 2100 & & 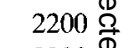 \\
\hline & & 313 & Lower & P2 & 2000 & 2045 & 2130 & $2230 \stackrel{8}{2}$ \\
\hline & & 337 & Lower & P3 & 2000 & 2045 & 2130 & 2230 으 \\
\hline & & 344 & Lower & P3 & 2100 & & 2115 & 22158 \\
\hline & & 385 & Lower & P3 & 2000 & 2045 & 2130 & 2230 응 \\
\hline & & 413 & Lower & P3 & 1930 & 2015 & 2115 & $2230 \leftrightharpoons$ \\
\hline & & 414 & Lower & P3 & 1930 & 2015 & 2115 & $2230 \stackrel{\circlearrowright}{\rightleftharpoons}$ \\
\hline & & 419 & Lower & P3 & 2030 & 2045 & 2130 & $2215^{\circ}$ \\
\hline & & 445 & Burn & $\mathrm{P} 2$ & 2000 & 2045 & 2130 & 2230 \\
\hline & & 471 & Burn & P3 & 2000 & 2045 & 2130 & 2230 \\
\hline
\end{tabular}

limit.

By this time it was realistic to include cases evacuated post-operatively from Field Hospitals so that with invaluable assistance from the Nursing Umpires $F$ Med 26B (Field Nursing Card) and F Med 26C (Field Surgery Card) were prepared to go with the $F$ Med 26s for a number of such cases (Fig 4, $5 \& 6$ ).

\section{Results}

Preplanning enabled casualties in proportions appropriate to casualty estimates to be admitted to the hospitals being exercised, suitably adjusted to the training needs of the hospitals.

1. It is practical and possible for exercise casualties to be fully and appropriately documented when they reach the hospital being exercised. A good working relationship between the hospital being exercised, the Casualty
Controlling Officer, the exercise DS and the Casual Simulation Team is vital, and the results of it impressives There is no place for the use of bogus names on exercise medical documents. The extension of the library of Med 26 etc to include documentation on ambulancक्ष trains is desirable.

2 . There was general and consistent appreciation from the hospitals being exercised, in particular the ability vary the casualty input to load particular departments $\dot{\phi}^{t}$ the request of the Commanding Officers. There was welcome constructive criticism which helped to correst errors early. There were regrettable gaps in the casualty flow due to nominated exercise casualties not reporting. Proper preparation of the casualties to be injected intori hospital exercise leads to a realistic input and to the correct lessons being learned. The exercise must last long enough for proper routines to be established and 


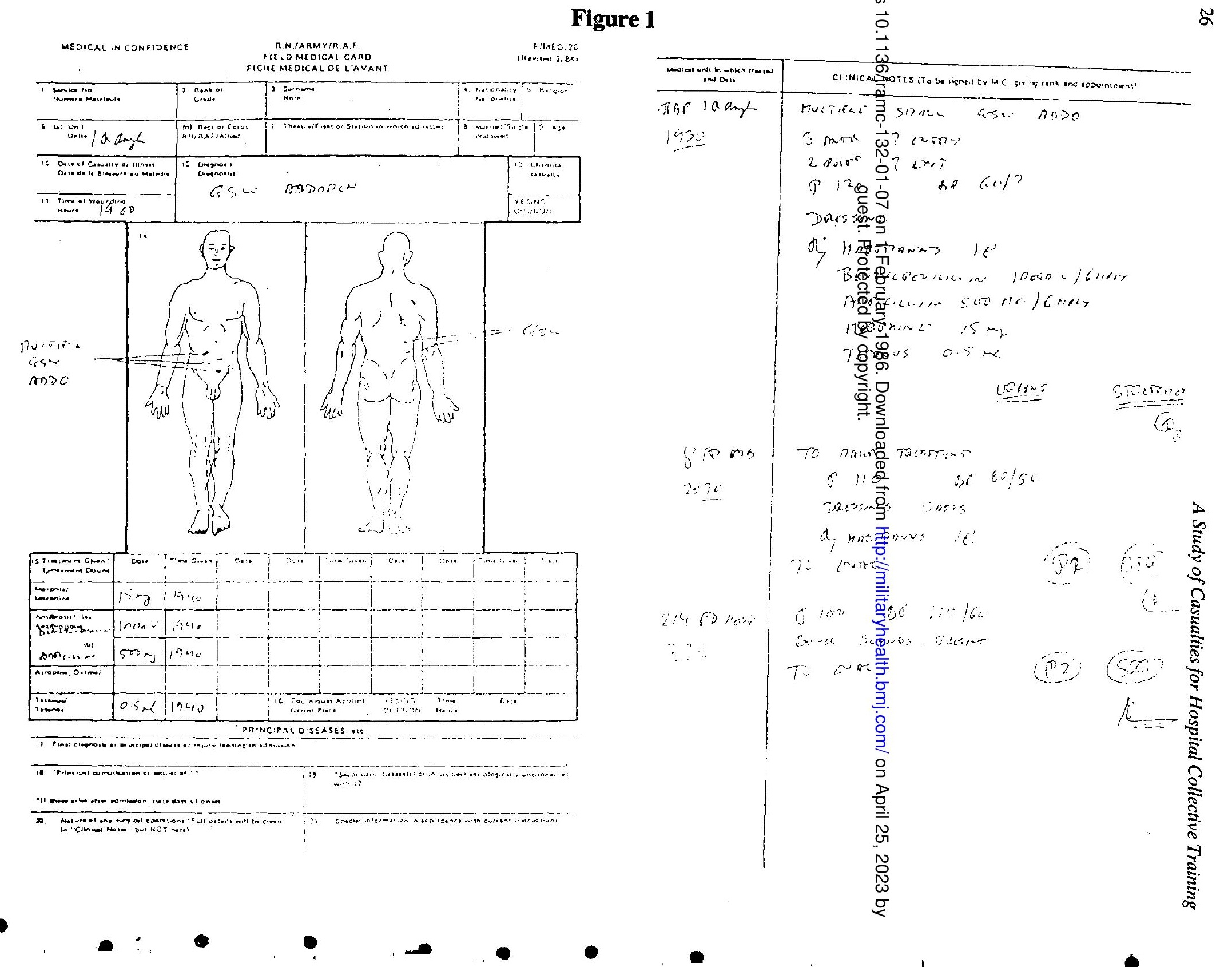




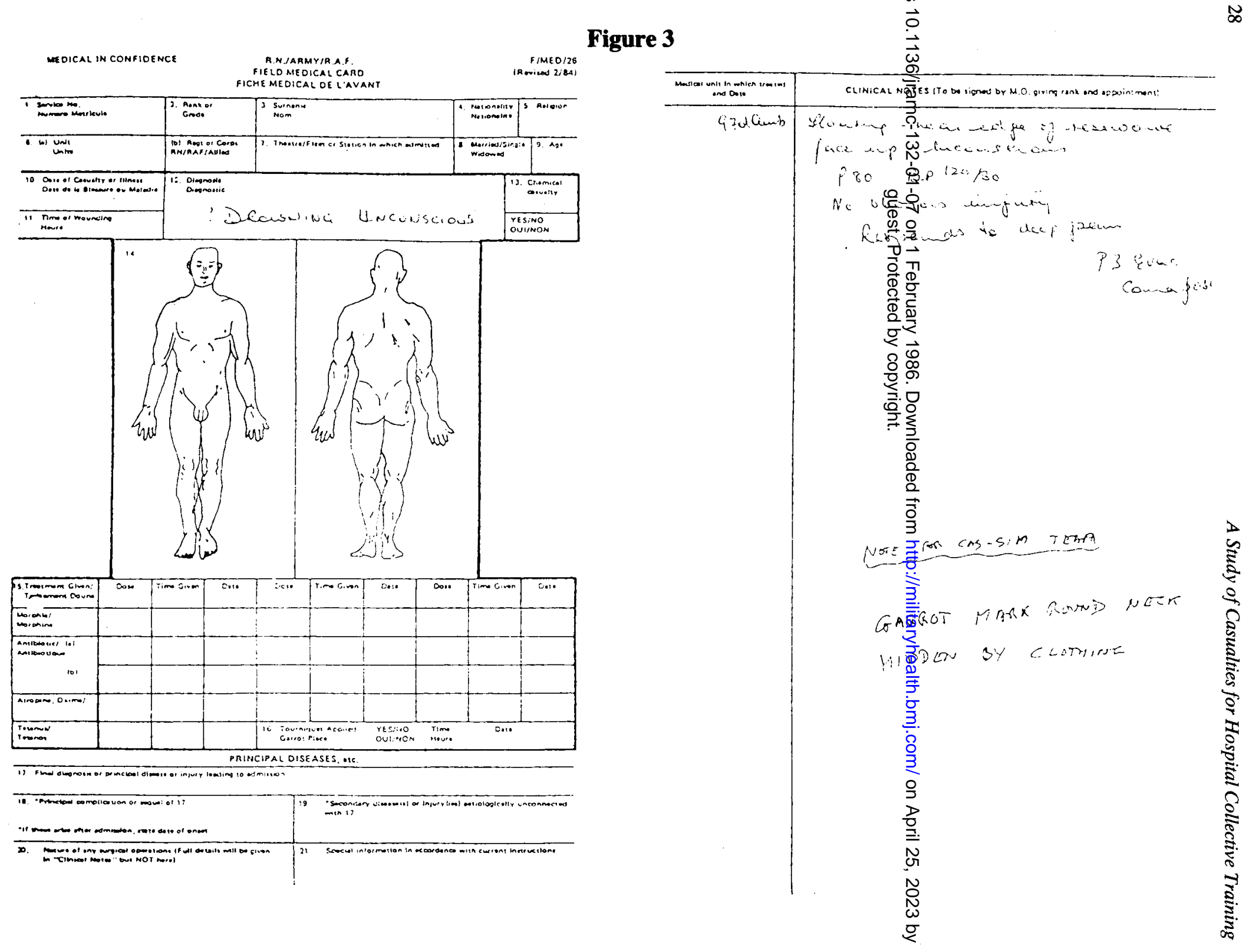




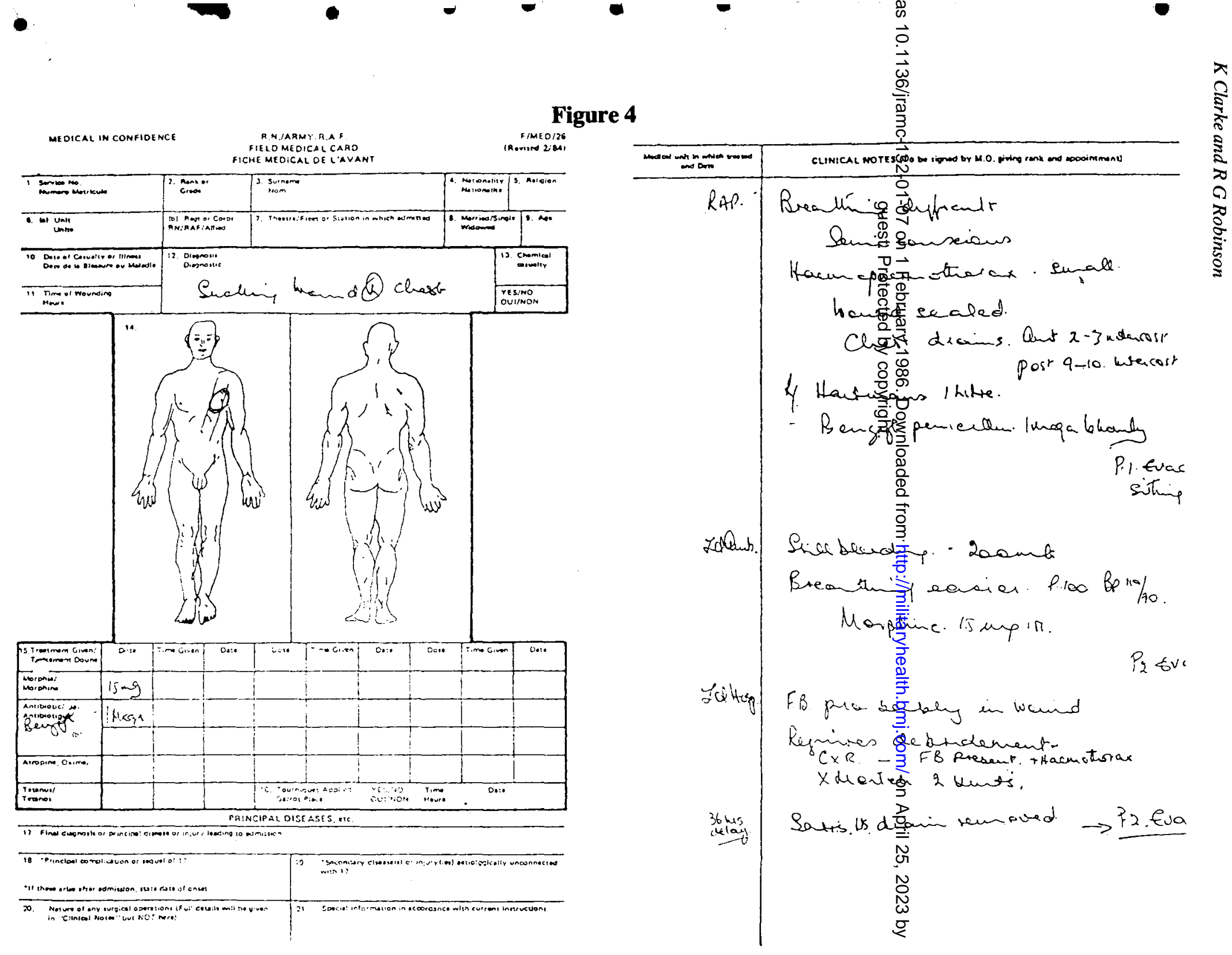




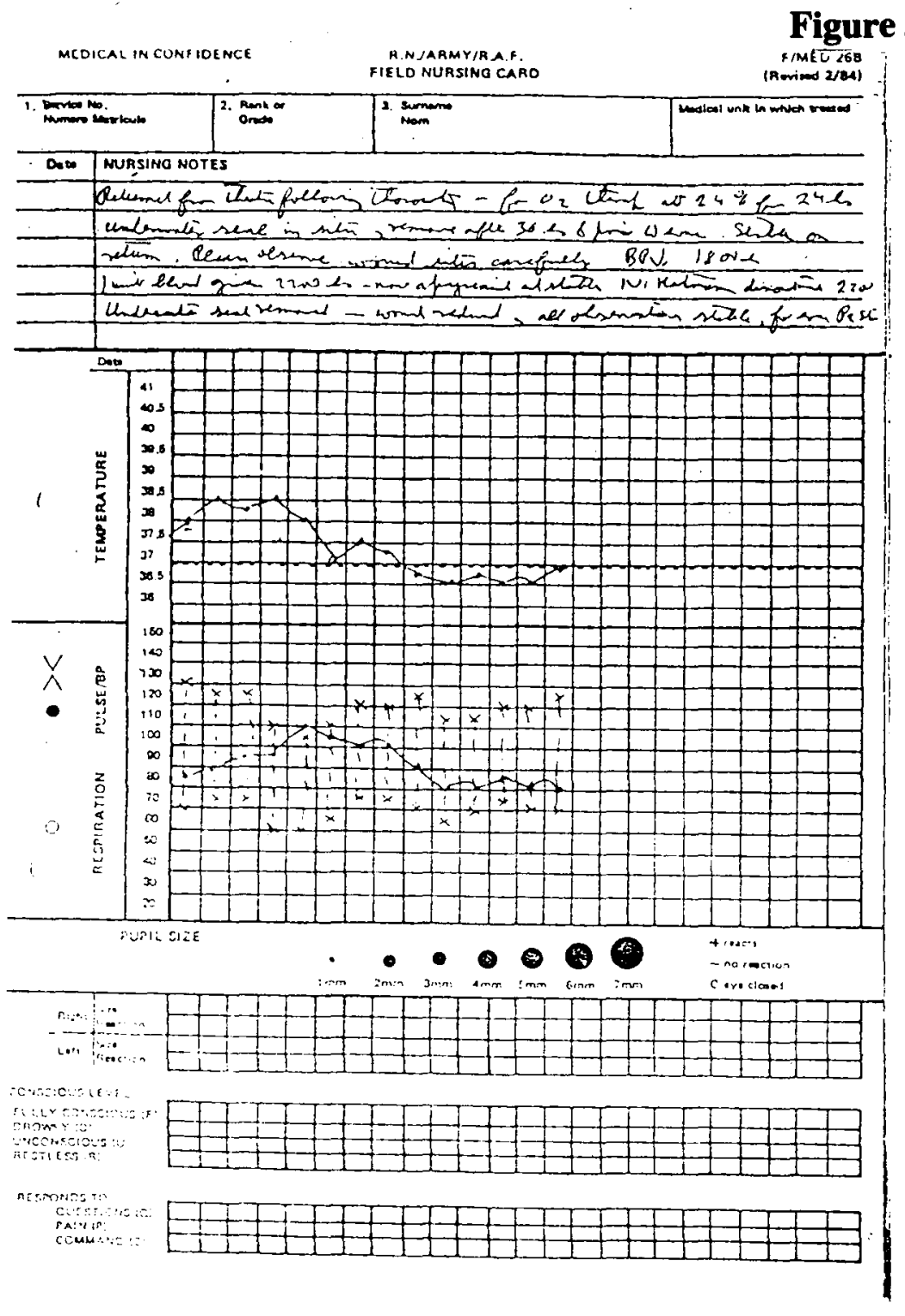

5

DATE

Anance ctarat

\begin{tabular}{|c|c|c|c|c|c|c|c|c|c|}
\hline \multirow[t]{3}{*}{ DATE } & \multirow[t]{3}{*}{ nime } & \multicolumn{4}{|c|}{ intaxe } & \multicolumn{3}{|c|}{ oumr } & $\because$ \\
\hline & & \multicolumn{2}{|r|}{ OAAL } & \multicolumn{2}{|c|}{ entravenous } & JaINe & vomit & ruak & \multirow{2}{*}{ NOTES } \\
\hline & & $m$ & Manere of Fivite & -1 & 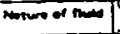 & 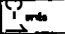 & mh & $-\infty$ & \\
\hline & 140 & & & & renas & $\omega$ & & & \\
\hline & 1600 & $\sin$ & wath & $1-$ & Beond & 6 & 170 & & Bele $\operatorname{sen} x$ \\
\hline & 2200 & 100 & wis & & 60 & 250 & & & Trace porsen \\
\hline & $03 / 5$ & 10 & in & & ㄷำ & $\checkmark$ & & & \\
\hline & 0600 & $2 \pi 0$ & $\sin$ & & का & 920 & & & NAD? \\
\hline & $0>0$ & 150 & oringe & & 0 & $\rightarrow$ & & & \\
\hline & 1000 & 20 & in & & 이 & $\pi$ & & & \\
\hline & 1300 & 20 & $\bar{E}$ & 7 & ¿ी) & 950 & & & ins \\
\hline & 1500 & 150 & orang & 100 & Hach $=\Phi$ & $\frac{c}{d}$ & & & \\
\hline & 1900 & 200 & $E_{n}$ & & $\angle \sigma$ & 360 & & & was \\
\hline & 2200 & 200 & $E_{n}$ & Gou & 4 & $\frac{100}{60}$ & & & I' dixand \\
\hline & 0300 & 150 & oranr & & 잉 & $\infty$ & & & \\
\hline & 0600 & 20 & G & & $\leq$ & 450 & & & \\
\hline & 1000 & 20 & $\operatorname{con}$ & & 믁 & 200 & & & \\
\hline & & & & & $?$ & 5 & & & \\
\hline & & & & & & $\overline{0}$ & & & \\
\hline & TOTAL & & & & & 带 & & & \\
\hline
\end{tabular}

FLUIOS TO BE GIVEN OVER PERIOD OF YHIS CMURT

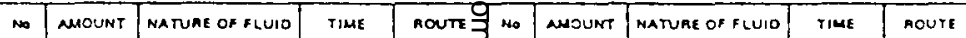

\begin{tabular}{|c|c|c|c|c|c|c|}
\hline & & & & & & \\
\hline 1 & $1000 \mathrm{M}$ & Honto ares & $12 \mathrm{nms}$ & 小 & 4 & \\
\hline 2 & Invi? & Q ovos & 4 nNs & 17 & 5 & \\
\hline
\end{tabular}

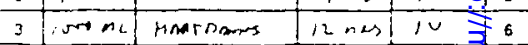

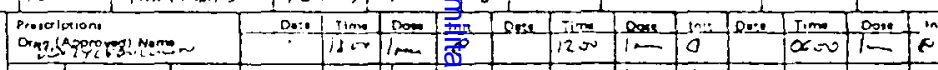

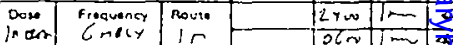

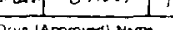

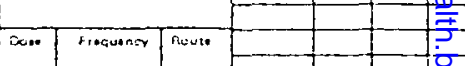

产.

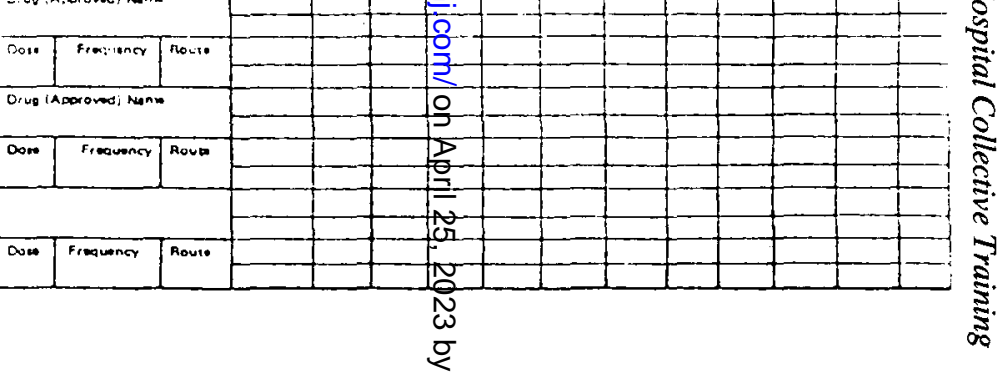




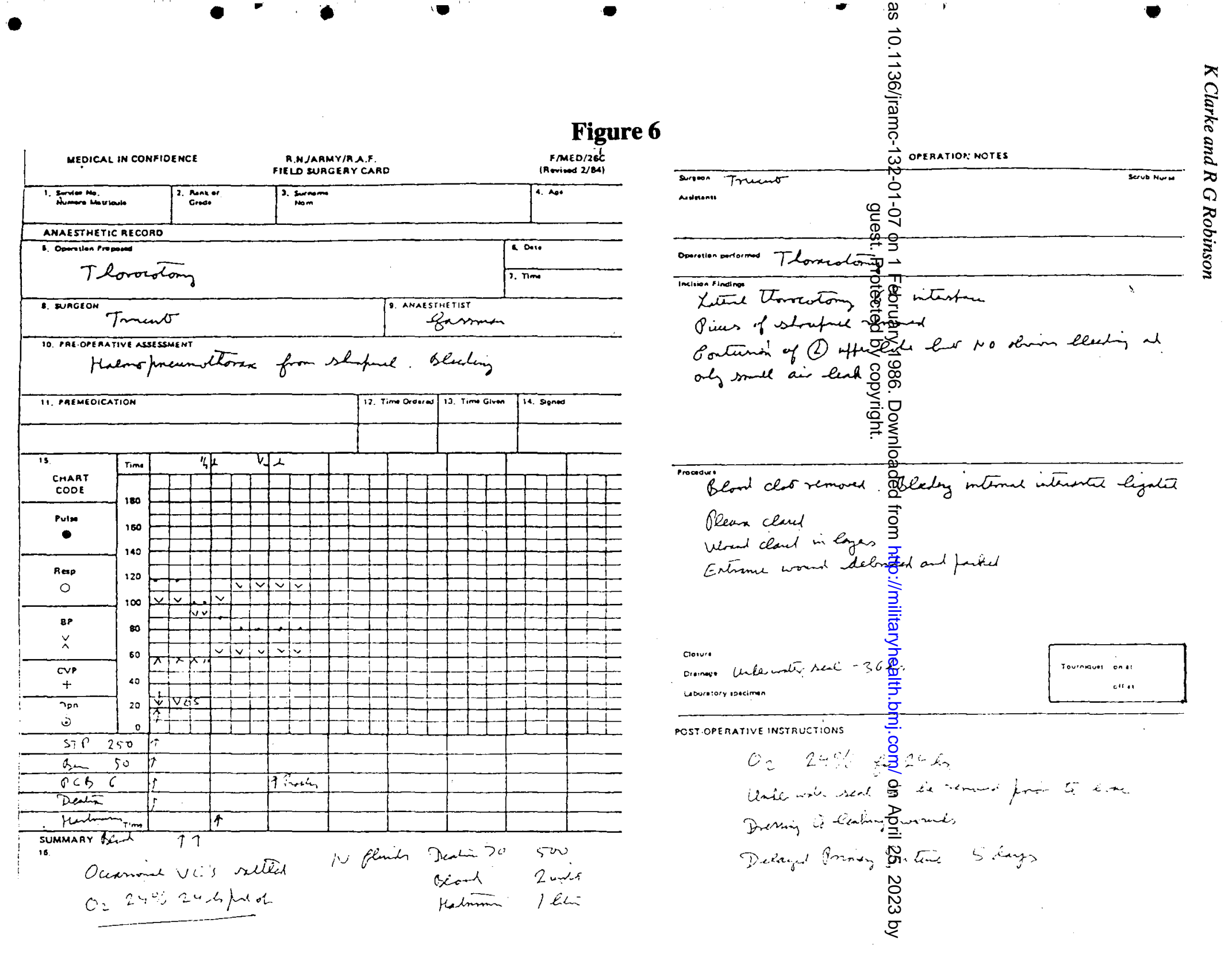


for post-operative patients to reach a General Hospital in a credible time-frame. A proper balance must be struck between maintaining the momentum of the exercise, while allowing the hospital an opportunity to reorganise itself in the light of experience.

3. An adequate supply of exercise casualties is essential, and they must be properly briefed and properly fed. The exercise casualties and the Officers and NCOs accompanying them must be briefed on the exercise and on the importance to the training of the hospital of the part which the exercise casualties would play. The hospital being exercised must have an unambiguous briefing of the "ground rules" for the feeding of casualties (where and when) and on the use of bottles and bedpans.

4. A photocopier is essential at casualty directing staff headquarters. Casualty cards must reach casualty simulation areas as early as possible, over an hour before the input of a group of twenty cases. An enthusiastic and efficient Warrant Officer to co-ordinate casualty simulation and despatch is invaluable.

Subsequent audit of documents removed from casualties evacuated from hospitals showed -

a. some scrappy note writing;

b. some departures from Casualty Treatment Regimes;

c. some patients evacuated with inadequate treatment having been given considering the time and distance to the next chance of hospital treatment.

An adequate library of F Med 26 s is essential.

The possibility of basing the casualty card library on a computer or word processor should be investigated, bearing in mind however the added realism of an F Med 26 completed in manuscript, and the need to match the casualty input to the battle scenario and the hour by hour training needs of the hospital being exercised.

\section{Envoi}

The Project Officer writes "in October 1984, as a result of my complaints about casualty welfare and casualty simulation on Ex Lionheart and Ex Petit Mash 1983 Brigadier Robinson asked me if I would be willing to act as Casualty Control Officer for Exercise Petit Mash 85. If I had had the wisdom of hindsight I would have been a reluctant volunteer but having agreed I found it a most interesting and instructive exercise and perhaps more TA Training Officers should be encouraged to take an active interest in casualty simulation and control".

The Inspector of Training AMS TA visited a TA General Hospital training in September 1985 and found them to be successfully using casualty cards from the project.

\section{Acknowledgments}

The Project Officer and Commander Headquarters Army Medical Services Territorial Army wish to acknowledge the great help and support given to this project from many sources, in particular, the data supplied by the Director of Army Surgery, the list of battle casualties prepared by Lieutenant Colonel $\mathrm{L}$ Lillywhite, MBE, RAMC, the cheerfulness and forebearance of the exercise casualties on the "Petit Mash" exercises, the casualty simulation teams from 16 Field Ambulance, and the splendid Warrant Officer I/C, WO1 A S Berry RAMC.

\section{Note by the Professor of Military Psychiatry}

Unfortunately at the time when this project was undertaken the Casualty Template had not been promulgated. This was done on the 6 June 1985. The template makes clear that, whatever the scenario, unrecovered combat stress reactions (battleshock cases) will pass through $\mathrm{RCZ}$ General Hospitals in substantial numbers ranging from 1:30 to 1:15 of surgical cases. The "evac to hosp" cases are additional to those which may arise from local incidents, which are correctly shown in Table IV, or may inadvertently be brought in by the RCZ Field Ambulances (Table III). In other words Table II should show 25 battleshock cases where at present it shows none. By the same token Table VI should contain at least one if not two battleshock cases.

It is particularly important that this realism should be maintained on exercises not only so that hospital staff learn the correct clinical and organizational management of battleshock cases but also so that they have this aspect of battlefield medicine constantly in mind. If not, doctors and nurses alike regularly miss the cases which present heavily disguised as a physical disorder. This happens over and over again both in peace and in war. 


\section{Note from DMSD}

\section{EXERCISE CASUALTIES - HOSPITAL}

\section{COLLECTIVE TRAINING}

The AMS TA paper rightly attempts to provide a realistic exercise workload for general hospitals but does not go far enough in constructing the likely casualty intake. General hospitals are deployed in 3 different situations demanding 3 separate casualty intake templates:

a. In the Rear Surgical Complex (RSC).

b. In the Rear Combat Zone (RCZ).

c. In the RCZ but reinforced with specialist teams.

This differentiation is important as the simplified casualty flow diagram below will demonstrate. In particular the AMS TA paper takes no cognizance of the flow of post operative Priority 2 casualties from the RSC.

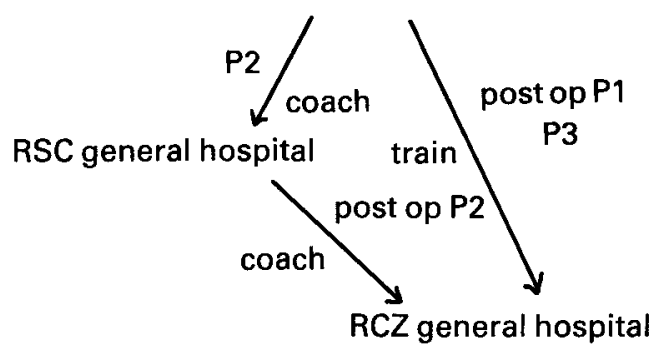

Having said that the paper is a commendable step in the right direction to correct a long standing weakness in war hospital exercises. It has highlighted the problem of adequate documentation and 'clinical input' from preceding echelons of medical care. Without the right casualty input, including relevant documentation, the major hospital exercises are wasted.

The Medical Directorate plans to have produced, by the end of 1986, a casualty evacuation chain model which will identify the appropriate templates for each type of hospital in all echelons. Armed with this AMS TA will be able to refine and complete the good work they have done so far.

\section{JOURNALS/PUBLICATIONS RECEIVED}

The following Journals/Publications have been received and are available in the Royal Army Medical College Library.

\section{JOURNALS}

Archives of Surgery; Annals of Clinical Research; Annals Chirugiae et Gynaecologiae; Australian \& New Zealand Journal of Surgery.

British Medical Journal; Bulletin of the World Health
Organisation; Boletin de la Oficina Sanitar Panamericana; Bulletin of the Pan American Healt Organisation; Bulletin of Endemic Diseases (Min. 需 Health, Baghdad, Iraq); Bulletin of the Academy of Military Medical Sciences, Beijing, China; Centr\& African Journal of Medicine; Genitourinary Medicine (British Medical Assocn); Giornale Di Medicina Militare.

Hellenic Armed Forces Medical Review; Indian Jouf: nal of Medical Research, The; Journal of the Roy Society of Medicine; Journal of the Royal Society ef: Health; Journal of Medical Virology; Journal International Medical Research, The; The Lancet.

Military Review; Medecene et Armees; Militaris Medicine; Medical Journal of Australia, The; Medecin $\vec{\ominus}$ Tropicale; Medicina Militar; National Defence Medicat Journal, Tokyo; Pakistan Armed Forces Medic Journal.

Quarterly Journal of Medicine; Royal Enginees Journal, The; Revista Del Servico De Sanidad De Laß Fuerzas Armadas: Royal Army Pay Corps Journat; Royal Pioneer, The; Revue Internationale Des Servicef De Sante; Revista Sanitaria Militaria; Revista De Sanidad De La Defensa Nacional.

Scottish Medical Journal; South African Medmed Journal: Tropical Diseases Bulletin; Transactions ind Studies of the College of Physicians of Philadelpbian Update-The Journal of the Postgraduate Gengra Practice; Ulster Medical Journal, The. Wehr-Medizinische Monatsschrift; World Heâㄴ. Forum - WHO; WHO Chronicle.

\section{PUBLICATIONS}

Bulletin of the International Civil Deferice Organisation; Environmental Health Criteria 43-50 Genitourinary Medicine - British Medical Assocro Management of Diarrhoea and use of Oral Rehydratiog Therapy - A Joint WHO/UNICEF Statement UNICEF; Medicine - International Agency fo항 Research on Cancer - Oxford Univ Press; Multiple Choice Tutor-Radiological Anatomy, Physics an Techniques-A Coral \& A $\mathrm{T}$ Irvine-Pub. Wmi Heinemann; Public Health Paper-Communit Response to Alcohol Related Problems - WHO No: 8 E. Quantity and Quality of Breast Milk-Report on the WHO Collaborative Study on Breast Feeding Supplement to WHO Chronicle Vol 39 - WHO Treatment and Prevention of Acute Diarrhoea - WHOF WHO Chronicle Vol. 39; WHO Regional Pubs. European Series No: 17 - WHO; WHO Technic Report Series No's: 714-729 - WHO. 